\title{
Scandals and safeguards
}

\section{Is scientific fraud on the increase?}

\section{The Great Betrayal: Fraud in Science}

by Horace Freeland Judson

Harcourt: 2004. 463 pp. $\$ 28$

\section{Daniel S. Greenberg}

The scientific enterprise is unquestionably afflicted by ethical, financial and bureaucratic woes, as often reported in Nature and elsewhere. But these problems are far worse than most of us realize, according to Horace Freeland Judson in The Great Betrayal, a brazen indictment of the condition of contemporary science.

Among scientists, the theft of intellectual property is "epidemic", Judson contends, and the enshrined processes of peer review for grants and publication have been rendered "moribund" by politics, cronyism and deceit. Furthermore, he asserts, the transition in research from healthy financial growth to a steady state is intensifying the difficulties. Judson acknowledges that the evidence for these stark assertions is scanty, because, like all clandestine, deviant behaviour, it is hard to measure precisely. "We have not yet found a way of getting at the true incidence of fraud in science," he observes.

No matter. Taking a tip-of-the-iceberg approach, Judson extrapolates from scores of documented episodes in the pantheon of scientific fakery, many of them also recounted in a 1983 book of similar title, scope and dour conclusions, Betrayers of the Truth by William Broad and Nicholas Wade (Simon \& Schuster). Judson revisits the hoary Piltdown hoax, the fakery mill that flourished in a prestigious cardiology laboratory at Harvard Medical School 25 years ago, and the fraudulent tissue-transplant reports that roiled the Sloan-Kettering Institute in the 1970s, along with others of comparable infamy.

Bringing the roll of dishonour up to date, Judson concludes that the rot is not merely episodic and occasional, but runs wide and deep. It is not, he says, the rarity supposed by Daniel Koshland when, as editor of Science in 1987, he brashly wrote that " $99.9999 \%$ of [scientific] reports are accurate and truthful". Psychopathology - the establishment aetiology for scientific misdeeds - is not the primary factor, Judson argues. Rather, the disorder is integral to modern science, inexorably arising from inadequate mentoring, veneration of high-volume publication, chases for grants and glory, political pressures for practical results, and insufficient budgets that inspire ethical shortcuts.

Along the way, Judson fires salvoes of derision at David Baltimore, best known to the public not for his Nobel prize but for

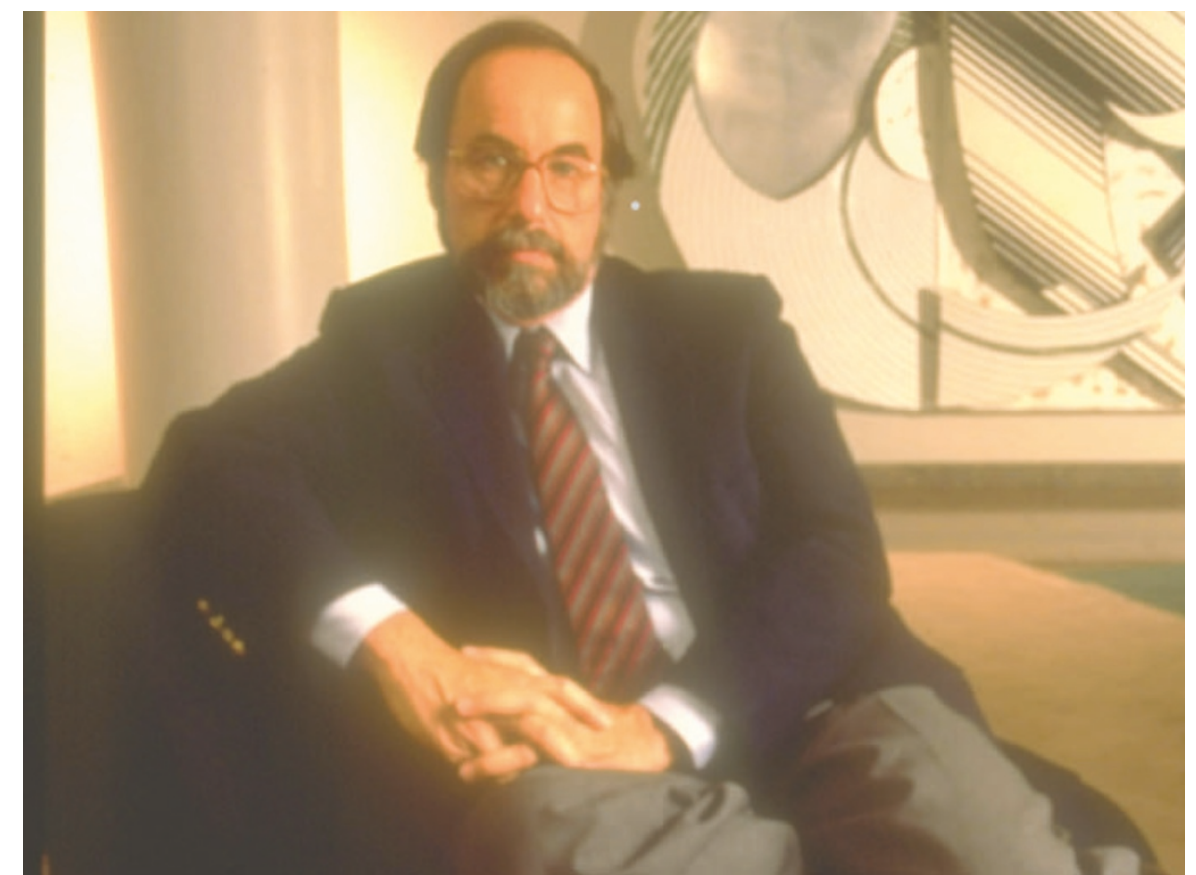

David Baltimore was embroiled in controversy when he defended a colleague accused of misconduct.

his tenacious, controversial defence of a research collaborator who was accused of misconduct but officially exonerated after a decade of government inquiries. It was the Baltimore case, Judson explains, that drew him to the trail of fraud in 1991. In this, the book that ensued, Judson gives Baltimore the lengthiest, most detailed attention, and even tells us that the Rockefeller University faculty "found the data in his proffered dissertation of borderline quality at best, thin."

Judson draws heavily on the literature of scientific delinquency. But curiously he makes no reference to the definitive work, The Baltimore Case (W. W. Norton, 1998) by Daniel J. Kevles, although Judson's book contrasts sharply with Kevles' exoneration of Baltimore. Judson, as others have before, charges Baltimore with arrogance and making misleading allegations of political interference in science. Baltimore, he states, could have ended the controversy at an early stage "by scrutinizing the disputed data and announcing that he was reconsidering the paper. This he refused to do."

From the Baltimore case and other eruptions, old and new, Judson infers that dangerous pathologies infest the culture of science. He says they have been little touched by government-mandated safeguards in recent years that call for the ethical tutoring of graduate students, protection of whistle-blowers, retention of laboratory records, and systematic enquiry into fraud allegations. More important than the guilt or innocence of individuals, Judson insists, "is the protection of the scientific process and of the integrity of the scientific record". These, he says, are increasingly neglected values in the intensely competitive world of modern science.

Judson certainly merits attention. A scholar and journalist with a wide acquaintanceship in the international scientific community, he is the author of a highly respected book, The Eighth Day of Creation (Simon \& Schuster, 1979), and is the founder and former director of the Center for History of Recent Science at The George Washington University.

His arguments, however, strike me as being far-fetched, dated and poorly aimed. Fraud in science, to the extent that it is calculable, seems to be no worse today than in previous times. It has perhaps been checked to some extent by the aforementioned safeguards and, as Judson notes, by the power of the Internet to detect plagiarism of text, if not of ideas. Steady-state funding may pose dangers, but current annual US government spending on biomedical research has risen to nearly $\$ 30$ billion, up from $\$ 12$ billion in 1996, when Judson and others bemoaned what they saw as an impending steady state. Meanwhile, California and other states are planning to spend large sums on stem-cell research and other areas of biotechnology.

The main threat to scientific purity today originates in corporate money and wiles aimed at co-opting the good name of science for the pursuit of profit, as revealed in recent 
pharmaceutical scandals. Withholding of clinical research data unfavourable to pharmaceutical products, concealment of financial interests in drug trials, ghosted papers for the promotion of drugs, and lucrative consulting deals for academic and medical 'thought leaders' are among the techniques that have surfaced. As former Harvard president Derek Bok laments in Universities in the Marketplace (Princeton University Press, 2003): "Most universities have not done all they should to protect the integrity of research. Many have not even shown they are seriously concerned about doing so."

Of these threats to the well-being of science, Judson says virtually nothing.

Daniel S. Greenberg is a guest scholar at the

Brookings Institution, Washington DC, USA.

$\mathrm{He}$ is the author of Science, Money, and Politics.

\section{A scientific feast}

\section{On Food and Cooking: The Science and Lore of the Kitchen, 2nd edition}

by Harold McGee

Scribner/Hodder \& Stoughton: 2004. 896 pp.

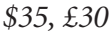

\section{Hervé This}

When On Food And Cooking was first published in 1984 it became a best-seller in English-speaking countries, and deservedly so. This was after Nicholas Kurti and I began our first experiments in the kitchen but before we coined the phrase 'molecular gastronomy' - the discipline now has its own national and international workshops, conferences, courses and seminars. Molecular gastronomy isn't just concerned with cooking; it is the part of food science that relates to gastronomy in general. According to the French gastronome Jean-Anthelme Brillat-Savarin: "Gastronomy encompasses all knowledge about man as he is eating."

Food science has a long history. Some 2,000 years ago, the anonymous author of the London papyrus used a balance to find out whether fermented meat weighed less than fresh meat, because of some 'emanation' that is lost. Much later, Antoine Parmentier, Michel-Eugène Chevreul, Benjamin Thomson (Count Rumford), Emil Fischer and others made remarkable contributions. Their work became very popular. For example, around the time of the Second World War, Edouard de Pomiane, a biologist at the Pasteur Institute, was writing best-sellers on food science in France.

In the same tradition, Harold McGee started publishing his books. I confess that I am not an impartial judge: he is a friend and one of the core participants of a series of international workshops on molecular gastronomy that I have organized every two

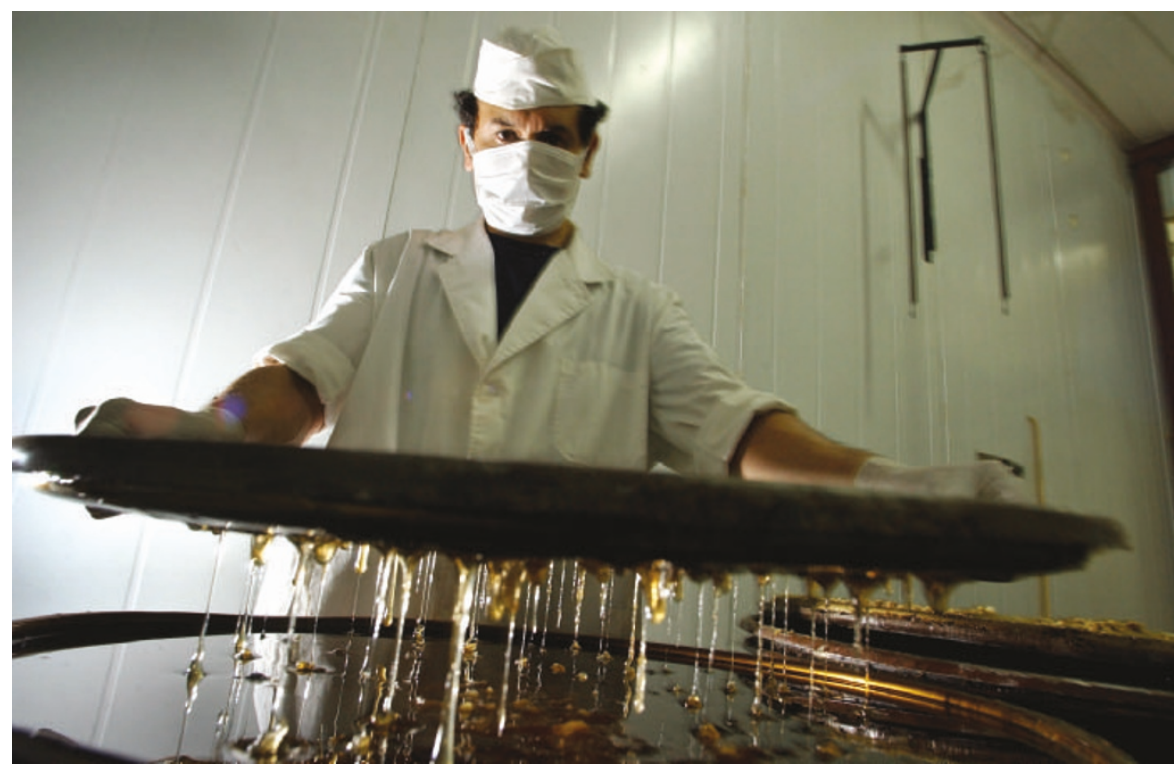

The sweet taste of success: honey has a wide range of culinary and medicinal uses.

years or so at the Ettore Majorana Centre for Scientific Culture in Erice, Sicily, since 1992.

What kind of information will a reader will find in his book? In the arbitrarily chosen chapter 12 , about sugars, chocolate and confectionery, there are sections on the history and nature of sugars; sugars and syrups; confectionery; and chocolate. In the section on sugars and syrups, we learn about honeybees and how they make honey (gathering nectar and transforming it) before finding out about processing and storing honey, its flavour, using it in cooking, honey and health, and infant botulism. There are boxes on the advance of the bee in North America and sweet ants, along with a picture of a honeycomb and a sketch of honey. As you can imagine, the book is a natural history of food and cooking.

The publisher's claim that this new edition is completely revised and updated really is true. I now understand why McGee has been so busy for the past few years: the new edition has nearly 900 pages full of detailed information on food, its production and its transformation during cooking. Not only has the book's physical appearance changed, but the table of contents has been extended and the text greatly modified. For instance, the first edition explained that the avocado "has been cultivated in Central America for perhaps 7,000 years", but the same section now begins by explaining that "the avocado tree Persea americana is a native of Central America and a member of the laurel family, a relative of the bay laurel, California bay, and sassafras". Instead of reading that "its fat content, at $20 \%$, is about 20 times the average for other fruits", we now learn that "avocado fruits are remarkable for containing little or no sugar or starch, and for being as much as $30 \%$ oil, the equivalent of well-marbled meat".

The book seems to be oriented mainly at cooks, probably because so many used the first edition. The text has been divided into small, easy-to-swallow sections; there are probably more cooking tips (but no recipes) than in the first edition; and the pictures are much improved (although they are in black and white). The scientific descriptions and explanations have been sharpened, and the references have been removed from the text and figure legends, and grouped together.

Of course, it is possible to criticize the book, but the reason for any imprecision is probably the lack of space: McGee had to distil the information and has given only the most useful. For example, he explains that astringency" is caused by a group of phenolic compounds consisting of 3 to 5 carbon rings, which are just the right size to span two or more normally separate protein molecules, bond them and hold them together". However, it is generally accepted that tannins with a relative molecular mass of about 5,000 could contribute to astringency. In addition, monomeric flavanols and some other simple phenolics such as gallic acid, which are not chemically defined as tannins, also precipitate proteins and are perceived as astringent. Finally, procyanidins become gradually less bitter and more astringent as their relative molecular mass increases. But then, I am fascinated by chemistry, whereas McGee was trying to summarize a wealth of information to provide only the main point for cooks.

Anyone seeking the scientific details could complement this book with the latest edition of the remarkable Food Chemistry by H. D. Belitz et al. (Springer, 2004). That new editions of these books have been published at the same time is probably no coincidence — molecular gastronomy is fashionable now in culinary as well as scientific circles.

Hervé This is in the INRA Group on Molecular Gastronomy, Laboratory of Chemistry, Collège de France, 11 Place Marcelin Berthelot, 75005 Paris, France. 